\title{
TEORES DE CARBOIDRATOS, PROTEÍNAS E AMINOÁCIDOS LIVRES DURANTE O DESENVOLVIMENTO DE RAÍZES TUBEROSAS DO FEIJÃO MACUCO (Pachyrrhizus tuberosus (Lam.) Spreng.), EM ÁREA dE VÁRZEA, AMAZONAS, BRASIL
}

\author{
Zilvanda L. de Oliveira MELO' ${ }^{2}$, Carlos Roberto BUENO ${ }^{2}$
}

\begin{abstract}
RESUMO - Entre as espécies que produzem tubérculos amiláceos nas condições tropicais, encontra-se Pachyrthizus tuberosus, leguminosa conhecida popularmente como feijão macuco ou jacatupé. Propós-se estudar alguns aspectos fisiológicos do desenvolvimento dessa espécic em uma área de várzea. Foi estudado o comportamento de três introduções $(2.2,1.2$ e 1.1.6) da coleção do programa de melhoramento de hortaliças do Instituto Nacional de Pesquisas da Amazônia - INPA (definidas como 1, 2 e 3), submetidas a duas formas de manejo: com e sem tutoramento das plantas e com e sem poda das inflorescências. A poda das inflorescências resultou em um aumento nos teores de xilose, glicose, açúcares redutores, proteinas e aminoácidos ao longo do desenvolvimento. Foram observadas variações nos teores de xilose, açúcares redutores e proteinas entre as introduções estudadas. $\mathrm{O}$ teor de amido nas raizes tuberosas não mostrou variação ao longo do desenvolvimento, em nenhum dos tratamentos estudados.
\end{abstract}

Palavras chaves: Leguminosă, Tutoramento, Poda de Inflorescência, Tuberização, Amazônia.

Carbohydrates, Proteins and Free Aminoacids Content During the Development of Tuberous Root on Yam Beam (Pachyrhizus tuberosus (Lam.) Spreng. ), Cultivated at the Floodplain Area, Amazonas State, Brazil

ABSTRACT - Among the species of plants that produce tuberous starched roots in the tropical region, Pachyrrhizus tuberosus, leguminous plant, which is popularly named "feijão macuco", "jacatupe" or yam bean. This study proposed to identify some physiological aspects of the yam bean cultivated in foodplain areas (várzeas). Three different genetic materials $(2.2,1.2$ and 1.1.6) studied by the breeding program of National Institute for Amazonian Research (INPA) (numbered 1, 2 and 3), were submitted to two different kinds of cultivation methods: with and without tutoring and with and without inflorescence pruning. Inflorescence pruning improved the xilose, glicose, reduced sugars, protein and aminoacid contents. The genetic materials did not present differences in terms of plant development, but some variations of xilose, reduced sugars and protein contents were observed among them. The starch content in the roots did not present variation during the plant growth under any of the treatments studied.

Key Words: legume, tutoring, inflorescence pruning, root formation Amazonia.

\section{INTRODUÇÃO}

O cultivo de tuberosas adaptadas às condições climáticas regionais é importante tanto como fonte de alimentação suplementar, como diversificação do mercado.

Entre as espécies amiláceas tropicais, encontra-se Pachyrrhizus tuberosus, conhecida popularmente como feijão macuco ou jacatupé, pertencente à familia das leguminosas. Planta herbácea, trepadeira, de crescimento indeterminado, podendo atingir até $3,50 \mathrm{~m}$ de altura. $\mathrm{O}$ fruto é um legume não comestivel. Desenvolve-se em todo o trópico úmido, não sendo exigente quanto à fertilidade do solo; seu ciclo reprodutivo é de aproximadamente oito meses.

Desta espécie, a parte comestivel são as raizes tuberosas, cujo potencial nutritivo chega a ser expressivo, contendo em

2 Instituto Nacional de Pesquisas da Amazônia - Caixa Postal 478 CEP 60.011-970 - Manaus AM 
média 6,5 a $8,9 \%$ de proteinas e $54 \%$ de amido (Noda, 1979; Noda et al., 1984; Sales,1993). No entanto, é muito raro encontrar a planta sendo cultivada por agricultores da região. Bolato et al. (1985) mostraram que as sementes contém três tipos de rotenóides, identificados como paquirrizina, rotenona e erosona. Devido ao efeito inseticida destas substâncias, esta parte da planta não pode ser utilizada como alimento.

A espécie $P$. tuberosus utiliza as raízes como órgão de reserva, e pouco se sabe como é feita a mobilização dos açúcares dentro da planta ao longo de seu desenvolvimento.

Alguns trabalhos mostram que a prática da desfolha induz alterações fisio-metabólicas profundas nas relações fonte-dreno, como por exemplo na síntese e distribuição de fotoassimilados (Hanson \& West, 1982; Pandey, 1983; Wilkerson et al., 1984; Pechan \& Morgan, 1985).

Furtado \& Corrêa (1988), estudando seis cultivares de mandioca (Manihot esculenta Crantz), submetidas a duas condições de manejo (sem e com poda da parte aérea), realizaram duas colheitas: uma aos quatro meses e outra aos 18 meses após o plantio. Os autores verificaram que a poda realizada aos quatro meses de idade afetou a produção de raizes e o teor de amido, somente aos dezoitos meses, com reduções de $37,5 \%$ e $3,6 \%$, respectivamente. Para o desenvolvimento da parte aérea, a poda foi prejudicial nas duas idades de colheitas, sendo seu efeito mais acentuado nas plantas mais novas.

Mazliak (1976), estudando o acúmulo de açúcares em beterraba, constatou que as folhas produzem por fotossintese, essencialmente açúcares redutores e, a sacarose é produzida maciçamente nas células do colo da raiz, da mesma forma que o acúmulo de amido se dá a partir desses açúcares redutores.

Os dados obtidos pelo Instituto de Tecnologia de Alimentos de São Paulo (Sales, 1993) mostraram que a espécie P. tuberosus apresenta, como base de matéria seca das raizes tuberosas, $45 \%$ de açúcares, $54,84 \%$ de amido e $27,09 \%$ de polissacarideos. A composição protéica das sementes, com base em matéria seca, foi em média $30,43 \%$ nas plantas cultivadas pelo INPA e, $22,25 \%$ nas plantas cultivadas pela UNICAMP, em Campinas, SP. Já os valores encontrados para as raizes e farinha foram $9,46 \%$, em média.

Antes de entrar em senescência, a folha exporta seus últimos produtos fotossintetizados e parte de suas próprias reservas, no caso aminoácidos provenientes da hidrólise de suas proteinas (Mazliak, 1976).

Este trabalho teve como objetivo estudar alguns aspectos físiológicos do desenvolvimento das raizes tuberosas de três introduções de $P$. tuberosus, notadamente os teores de açúcares solúveis totais, amido, aminoácidos livres e proteínas.

\section{MATERIAL E MÉTODOS}

Foram utilizadas três introduções da Coleção do Programa de Melhoramento de Hortaliças do Instituto Nacional de Pesquisas da Amazônia, identificadas como $2.2 ; 1.2$ e 1.1.6, mas que para facilitar a interpretação foram chamadas respectivamente de 1,2 e 3 . O material genético básico foi originário do 
interior do Estado do Amazonas e do México, mas foram reproduzidos e selecionados na Estação Experimental de Hortaliças, localizada em Manaus, AM.

Este estudo teve como objetivo analisar duas formas de manejo: uso de tutoramento e poda das inflorescências. $\mathrm{O}$ trabalho foi desenvolvido na Estação Experimental do Ariau - Município de Iranduba, AM, uma área de várzea localizada na margem esquerda do Rio Solimões, distante cerca de $30 \mathrm{Km}$ de Manaus, com solo predominante do tipo Gley Pouco Húmico.

O experimento de campo foi realizado no período de agosto de 1993 a maio de 1994, período em que as várzeas estão disponíveis para utilização.

$\mathrm{O}$ delineamento experimental foi o de blocos ao acaso, em esquema fatorial $3 \times 2$ X 2 (três introduções, com e sem tutor, com e sem a retirada das inflorescências), utilizando-se o espaçamento entre linhas de $1,0 \mathrm{~m}$ e entre plantas de $0,5 \mathrm{~m}$. Cada parcela contou com 60 plantas úteis, no inicio do ensaio.

O ensaio foi implantado por semeadura direta no campo, utilizandose duas sementes por cova, uma vez que as introduções apresentaram alta porcentagem de germinação. Os tratos culturais e sanitários foram executados quando se fizeram necessários.

$\mathrm{O}$ tutoramento iniciou-se quando as plantas apresentavam o seu terceiro par de folhas trifolioladas, usando como tutor varas de madeira. A poda das inflorescências foi realizada semanalmente, quando as mesmas encontravam-se na fase de botão floral.

Os dados climatológicos, incluindo temperatura máxima, mínima e temperatura média $\left({ }^{\circ} \mathrm{C}\right)$, umidade relativa do ar(\%)e precipitação $(\mathrm{mm})$, foram coletados no posto meteorológico da EMBRAPA/INPA/MAX-PLANCK, situado na fazenda Caldeirão, vizinho da área experimental em estudo.

Para as análises bioquímicas, foram coletadas mensalmente três repetições de uma mesma parcela e homogeneizada, sendo cada amostra (em torno de $0,5 \mathrm{~g}$ de tecido fresco), colocada em etanol $80 \%$ e guardada em freezer até o momento das análises bioquímicas. Foram determinados os teores de açúcares solúveis totais, açúcares redutores, aminoácidos livres, proteínas e amido.

Os carboidratos e aminoácidos livres foram extraídos mediante o uso do etanol $80 \%$ a quente e submetidos à centrifugação.

O método utilizado para a dosagem de açúcares solúveis totais foi o fenol-sulfúrico, segundo Dubois et al. (1956). As reações de cor, quantificadas nos carboidratos e aminoácidos foram feitas mediante uso de um espectrofotômetro "VARIAN", Série 634. As absorbâncias foram lidas a $480 \mathrm{~nm}$ e $490 \mathrm{~nm}$ e as concentrações de açúcares calculadas em função das curvas padrões, onde utilizou-se xilose na faixa de 10 a $90 \mu \mathrm{g}$ e glicose também na faixa de concentração de 10 a $90 \mu \mathrm{g}$. Para cada curva padrão foi obtida uma equação da reta.

Para a dosagem dos açúcares redutores, seguiu-se o método colorimétrico de Nelson (1944). As absorbâncias foram obtidas a $540 \mathrm{~nm}$, sendo a curva padrão determinada com soluções de glicose de 10 a $90 \mu \mathrm{g}$. 
A determinação dos aminoácidos seguiu a metodologia de Yemm \& Cocking (1955). As leituras foram feitas a $570 \mathrm{~nm}$. Para a curva padrão utilizou-se glicina na faixa de concentração entre 0,1 a $0,8 \mathrm{mg}$.

A fração protéica foi determinada a partir do precipitado obtido após a extração do extrato etanólico. A dosagem de proteinas contida no extrato foi feita segundo o método de Goa (1953). As leituras foram determinadas a $330 \mathrm{~nm}$. Para a curva padrão utilizou-se yglobulina bovina com concentrações entre 0,2 e $4,0 \mathrm{mg}$, sendo então obtida a equação da reta para o ajuste dos pontos.

Para a hidrólise do amido, utilizou-se o precipitado proveniente da extração das proteinas. Apọ́s a digestão do amido, a determinação seguiu o método de Mccready et al. (1950), com fenol $80 \%$ e ácido sulfúrico concentrado. As absorbâncias foram lidas a 490 $\mathrm{nm}$ e os valores obtidos multiplicados pelo fator de correção 0,9 , para a conversão em quantidades de amido. Foram utilizadas soluções de glicose com concentrações entre 5 e $45 \mathrm{mg}$ para a realização da curva padrão.

Para a análise dos dados utilizouse o programa estatístico System Analysis Statistics (SAS, 1989). Na avaliação dos dados foi realizada análise de variância pelo teste $\mathrm{F}$ e comparação das médias pelo teste de Tukey ao nível de 5\% de probabilidade (Pimentel Gomes, 1977).

\section{RESULTADOS E DISCUSSÃO}

A análise estatistica revelou que o teor de amido não mostrou diferenças significativas em relação aos períodos de avaliação das plantas, formas de manejo, introduções ou interações (Tab. 1), No tratamento com manejo da inflorescência, aos 70 dias após a semeadura, os teores de xilose e glicose mostraram diferenças significativas, repetindo-se esse comportamento aos 160 dias. No entanto, aos 70 dias os valores mais elevados de xilose e glicose foram observados nos tratamentos com inflorescências, enquanto que aos 160 dias as plantas sem inflorescências apresentaram valores mais elevados.

Outras diferenças significativas foram verificadas entre as introduções: aos 70 dias para xilose e aos 160 dias para glicose, evidenciando que há variações bioquimicas entre os materiais genéticos estudados (Tab. 2).

Os teores de xilose, extraidos de plantas das introduções 1 e 3, aos 70 dias, não mostraram diferenças entre si, mas foram superiores à introdução 2. Quanto aos teores de glicose, as introduções 1 e 2, e 2 e 3 , não diferiram entre si aos 160 dias. Entretanto, a introdução 3 apresentou teores de glicose superiores à 1 . Analisando-se os teores de açúcares redutores, observa-se que aos 70 dias não ocorreram diferenças estatisticas entre as introduções 1 e 3 e entre 1 e 2; entretanto, a introdução 3 mostrou açúcares redutores estatisticamente superiores em relação à introdução 2; aos 130 dias também não ocorreram diferenças estatísticas entre as introduções 1 e 3 e entre 1 e 2; entretanto, a introdução 2 mostrou teores de açúcares redutores estatisticamente superiores em relação à 3 .

No que se refere aos teores de carboidratos, as três introduções apresentaram diferenças significativas 
Tabela 1. Teores de carboidratos em raizes tuberosas de plantas de feijão macuco, obtidas em função do tempo, em dias após a semeadura e manejo das inflorescências. Médias de nove amostras simples.

\begin{tabular}{|c|c|c|c|c|c|c|c|c|c|c|c|c|c|c|c|}
\hline \multirow{3}{*}{ Tratamento } & \multicolumn{5}{|c|}{ Xilose (mg/g MF) ${ }^{1}$} & \multirow{2}{*}{\multicolumn{5}{|c|}{$\begin{array}{l}\text { Glicose }(\mathrm{mg} / \mathrm{g} \mathrm{MF})^{1} \\
\left(_{(\mathrm{DAS})^{2}}\right.\end{array}$}} & \multirow{2}{*}{\multicolumn{5}{|c|}{$\begin{array}{c}\text { Açúcares redutores }(\mathrm{mg} / \mathrm{g} M F)^{1} \\
(\mathrm{DAS})^{2}\end{array}$}} \\
\hline & & & (DAS) & & & & & & & & & & & & \\
\hline & 70 & 100 & 130 & 160 & 175 & 70 & 100 & 130 & 160 & 175 & 70 & 100 & 130 & 160 & 175 \\
\hline Com infl. & $34,2 a$ & 37,5 & 42,6 & $42,1 b$ & 47,2 & $36,5 a$ & 39,5 & 44,5 & $43,9 b$ & 48,7 & 19,0 & 22,3 & $28,1 b$ & $25,7 b$ & 31,1 \\
\hline Sem infl. & $28,0 b$ & 36,7 & 45,1 & $49,3 a$ & 47,8 & $29,8 b$ & 38,5 & 46,6 & $50,9 a$ & 49,0 & 16,0 & 23,2 & $30,5 a$ & $29,0 a$ & 31,8 \\
\hline DMS & 4,71 & - & - & 5,15 & - & 5,02 & - & - & 5,80 & - & - & - & 2,33 & 2,81 & - \\
\hline
\end{tabular}

As médias seguidas pelo mesma letra não diferem estatísticamente entre si pelo teste de Tukey, ao nível de $5 \%$ de probabilidade.

1-(mg/g matéria fresca)

2-(DAS) - Dias após a semeadura

Tabela 2. Teores de carboidratos em raizes tuberosas de plantas de feijão macuco, obtidas em função do tempo, em dias após a semeadura e manejo das introduções testadas. Médias de nove amostras simples.

\begin{tabular}{|c|c|c|c|c|c|c|c|c|c|c|c|c|c|c|c|}
\hline \multirow[t]{2}{*}{ Introduções } & \multicolumn{5}{|c|}{$\begin{array}{l}\text { Xilose }(\mathrm{mg} / \mathrm{g} \mathrm{MF})^{1} \\
\qquad(\mathrm{DAS})^{2}\end{array}$} & \multicolumn{5}{|c|}{$\begin{array}{l}\text { Glicose }(\mathrm{mg} / \mathrm{g} \mathrm{MF})^{1} \\
\qquad(\mathrm{DAS})^{2}\end{array}$} & \multicolumn{5}{|c|}{$\begin{array}{l}\text { Açúcares redutores }(\mathrm{mg} / \mathrm{g} \mathrm{MF})^{1} \\
(\mathrm{DAS})^{2}\end{array}$} \\
\hline & 70 & 100 & 130 & 160 & 175 & 70 & 100 & 130 & 160 & 175 & 70 & 100 & 130 & 160 & 175 \\
\hline 1 & $33,4 a$ & 39,1 & 44,0 & 41,8 & 41,8 & 35,7 & 41,0 & 45,9 & $42,7 b$ & 50,2 & $18,8 a b$ & 24,8 & $29,7 a b$ & 27,6 & 32,4 \\
\hline 2 & $26,8 b$ & 35,0 & 44,5 & 46,4 & 46,4 & 29,1 & 36,8 & 46,1 & $47,8 \mathrm{ab}$ & 45,7 & $13,9 b$ & 21,8 & $31,6 a$ & 25,4 & 28,8 \\
\hline 3 & $33,1 \mathrm{a}$ & 37,4 & 43,0 & 48,9 & 49,1 & 34,6 & 39,5 & 44,6 & $51,7 a$ & 50,1 & $19,7 a$ & 21,6 & $26,6 b$ & 29,0 & 32,8 \\
\hline DMS & 6,99 & - & - & - & - & - & - & - & 8,60 & - & 5,6 & - & 3,46 & - & - \\
\hline
\end{tabular}

As médias seguidas pelo mesma letra năo diferem estatísticamente entre si pelo teste de Tukey, ao nível de $5 \%$ de probabilidade. 
entre si, com exceção do amido, que nã̃o mostrou variação no seu conteúdo. Esse resultado confirma as observações feitas por Alvarenga (1987), que também não encontrou variaçâo nos teores de amido na mesma espécie em estudo. Porém, com a retirada das inflorescências, ocorreu um maior acúmulo de açúcares solúveis totais e redutores nas raizes aos 160 dias, indicando que houve uma maior translocação nesta fase de carboidratos da fonte (folhas) para as regiões de consumo, no caso as raizes tuberosas.

Alvarenga (1987), ao estudar estes compostos nesta mesma espécie em duas épocas (outono e primavera), verificou que o plantio de primavera favoreceu de forma significativa o acúmulo destes compostos em vagens, sementes e raizes. Alvarenga \& Meirelles (1993), ao estudarem a composição química para o estabelecimento de um parâmetro entre o potencial nutritivo do feijão macuco com outras culturas de expressão econômica, encontrou valores para açúcares solúveis totais de $246,13 \mathrm{mg} / \mathrm{g}$ matéria fresca, açúcares redutores de 225,81 mg/g matéria fresca e para amido, $53,89 \mathrm{mg} / \mathrm{g}$ matéria fresca. Os valores referentes aos teores de amido coincidem com os valores encontrados por Sales (1993).

Aos 160 e 175 dias após semeadura, os teores de aminoácidos livres foram superiores nas plantas cujas inflorescências foram removidas, bem como nas plantas tutoradas aos 175 dias (Tab. 3).

Com relação aos teores de aminoácidos, observa-se aos 175 dias, que o tratamento com tutor associado à retirada das inflorescências apresentou um resultado estatisticamente superior às demais combinações estudadas (Tab. 4).

Estes resultados mostram que para os teores de aminoácidos ocorreu interação significativa entre os tratamentos tutor $\mathrm{x}$ inflorescência, aos 175 dias.

A retirada das inflorescências

Tabela 3. Teores de aminoácidos livres $\mathrm{cm}$ raizes tuberosas de plantas de feijào macuco, obtidas em diferentes periodos após a semeadura (DAS) e formas de manejo. Médias de nove amostras simples.

\begin{tabular}{lccccc}
\hline Tratamentos & \multicolumn{5}{c}{ aminoácidos (mg/g/MF )' } \\
& 70 & 100 & 130 & 160 & 175 \\
\hline Com tutor & 0,019 & 0,010 & 0,009 & 0,009 & $0,012 \mathrm{a}$ \\
Sem tutor & 0,020 & 0,010 & 0,010 & 0,010 & $0,008 \mathrm{~b}$ \\
Com inf. & 0,018 & 0,010 & 0,009 & $0,007 \mathrm{~b}$ & $0,008 \mathrm{~b}$ \\
Sem inf. & 0,020 & 0,010 & 0,010 & $0,011 \mathrm{a}$ & $0,013 \mathrm{a}$ \\
\hline DMS(tutor) & - & - & - & - & 0,002 \\
DMS(infi.) & - & - & - & 0,003 & 0,002 \\
\hline
\end{tabular}

As médias seguidas da mesma letra não diferem estatísticamente entre si pelo teste de Tukey, ao nivel de $5 \%$ de probabilidade.

1 -(mg/g matéria fresca)

2-(DAS) - Dias após a semeadura 
Tabela 4. Teores de aminoácidos livres em raizes tuberosas em plantas de feijão macuco, obtidos em função dos tratamentos, com e sem tutor com e sem inflorêscencia aos 175 dias após a semeadura. Médias de nove amostras simples.

\begin{tabular}{lcc}
\hline tutor & inflorescências & aminoácidos $(\mathrm{mg} / \mathrm{g} \mathrm{MF})^{1}$ \\
\hline Com & Sem & $0,016 \mathrm{a}$ \\
Sem & Sem & $0,010 \mathrm{~b}$ \\
Com & Com & $0,009 \mathrm{~b}$ \\
Sem & Com & $0,007 \mathrm{~b}$ \\
\hline DMS & & 0,02 \\
\hline
\end{tabular}

As médias seguidas pela mesma letra năo diferem estatísticamente entre si pelo teste de Tukey, ao nível de $5 \%$ de probabilidade.

1-(mg/g matéria fresca)

Tabela 5. Médias dos teores de proteina em raizes tuberosas de plantas de feijão macuco obtidas em função do tempo, em dias após a semeadura, introduções e manejo das inflorescências.

\begin{tabular}{llllll}
\hline & & \multicolumn{5}{c}{ proteínas $(\mathrm{mg} / \mathrm{g} / \mathrm{MF})^{1}$} \\
Tratamentos & 70 & 100 & 130 & 160 & 175 \\
\hline Introdução 1 & 79,5 & $58,6 \mathrm{a}$ & 42,2 & 33,7 & 40,0 \\
Introdução 2 & 81,1 & $52,0 \mathrm{ab}$ & 49,1 & 26,6 & 36,2 \\
Introdução 3 & 72,4 & $39,8 \mathrm{~b}$ & 39,5 & 34,4 & 53,8 \\
Com Inflor & 73,2 & 53,5 & 43,1 & $22,5 \mathrm{~b}$ & $3,14 \mathrm{~b}$ \\
Sem Inflor & 82,2 & 46,9 & 44,0 & $39,4 \mathrm{a}$ & $39,8 \mathrm{a}$ \\
\hline DMS (Intr.) & - & 12,8 & - & - & - \\
DMS (Infl.) & - & - & - & 12,6 & 13,8 \\
\hline
\end{tabular}

As médias seguidas da mesma letra não diferem estatísticamente pelo teste de Tukey, ao nivel de $5 \%$ de probabilidade.

1-(mg/g matéria fresca)

2-(DAS) - Dias após a semeadura

também resultou em maiores teores de proteinas aos 160 e 175 dias, conforme se observa na Tabela 5, havendo ainda, diferenças estatísticas entre as introduções já aos 100 dias.

Os resultados mostraram que a introdução 1 foi estatisticamente superior à introdução 3 , e que não ocorreram diferenças estatísticas significativas entre os teores de proteinas obtidos da introdução 1 e 2 e da introdução 2 e 3.
Os teores de aminoácidos e proteínas tiveram um aumento significativo com a retirada das inflorescências aos 160 dias após semeadura; porém, estes compostos continuaram a aumentar até os 175 dias, fato que não ocorreu com os carboidratos. Provavelmente houve uma mobilização destes carboidratos armazenados para a síntese de aminoácidos e conseqüente síntese de 
proteina. Conforme Benincasa (1986), por meio da fotossintese são produzidos produtos primários, ou seja unidades de carboidratos simples que poderão ser: i) armazenados na forma simples ou complexa; ii) usados na respiração; iii) e ainda utilizados na síntese de outros compostos como proteinas, lipídeos, etc.

Alvarenga (1987) encontrou quatro vezes mais proteinas nas raizes tuberosas de feijão macuco no plantio de outono que o obtido no plantio de primavera. Alvarenga \& Meirelles (1993) encontraram que os valores de proteínas das raízes tuberosas desse feijão superaram em até quatro vezes a mandioca e 2,5 vezes a batata. Estes valores chegaram a 12,05 mg de proteína/g de matéria seca. Para os teores de aminoácidos, Alvarenga (1987) encontrou níveis mais altos no plantio de outono: $309,44 \mathrm{mg} / \mathrm{g}$ matéria seca. Em outro experimento, conduzido no período de setembro a março, Alvarenga \& Meirelles (1993) encontraram valores de $122,29 \mathrm{mg}$ de aminoácidos /g de matéria seca.

\section{CONCLUSÕES}

Os resultados obtidos neste trabalho, dentro das condições desenvolvidas, permitem concluir que:

1- A retirada das inflorescências resultou em um aumento nos teores de xilose, glicose, açúcares redutores, proteinas e aminoácidos, ao longo do desenvolvimento.

2- As introduções mostraram diferenças significativas entre si nos teores de xilose, glicose, açúcares redutores e proteinas;

3- $\mathrm{O}$ teor de amido nas raízes tuberosas não mostrou variação ao longo do desenvolvimento, em quaisquer dos tratamentos estudados.

\section{AGRADECIMENTOS}

Os autores agradecem ao Sr. Wilson Wesen pelo apoio técnico e ao CNPq (Projeto 520751/93-0) e ao Instituto Max Planck (Projeto SHIFT ENV.14/ VÁRZEAS) pelo apoio financeiro.

\section{Bibliografia citada}

Alvarenga, A. A. 1987. Estudos de alguns aspectos do desenvolvimento do feijão jacatupé (Pachyrrhizus tuberosus (Lam) Spreng). Tese de Doutoramento, Universidade Estadual de Campinas, Campinas, São Paulo, 174p.

Alvarenga, A. A.; Meirelles, A. J. A. 1993. Caracterização química de sementes e raizes tuberosas do feijão jacatupé (Pachyrrhizus tuberosus (Lam) Spreng). In; IV Congresso Brasileiro de Fisiologia Vegetal. Rev. Bras. de Fisiol. Vegetal, 5(1):96.

Benincasa M. P. 1986. Análise de crescimento de plantas (noções básicas). São Paulo, Universidade Estadual Paulista. 41p.

Bolato, C. A.; Magalhães, E. G.; Válio, F. M. 1985. Rotenóides de Pachyrrhizus. In: Resumos da $37^{a}$ Reunião Anual da SBPC. Sociedade Brasileira para o Progresso da Ciência, Belo Horizonte, p. 508.

Dubois, M.; Gilles, K. A.; Hamilton, J. K.; Rebers, P. A.; Smith, F, 1956. Colorimetric method for determination of sugars and related substances. Analitical Chemistry, 3(26):350-356.

Furtado, M. J.; Corrêa, H. 1988. Infuência da poda no comportamento de seis cultivares de mandioca (Manihot esculenta Crantz), no estado do Espirito Santo. Ciência Prática, 12(1):55-65.

Goa, J. 1953. A micro biuret method for protein determination. Scand. J. Cli. Lab. Investigation., 5(48):212-222.

Hanson, W. D.; West, D. R. 1982. Source-sink relationships in soybeans. I. Effects of 
source manipulation during vegetative growth on dry matter distribution. Crop Sci., 22(2):372-376.

Mazliak, P. 1976. Fisiologia vegetal: nutrición $y$ metabolismo. Bacerlona, Ediciones Omega 350p.

Mccready, R. M.; Ducay, E. D.; Gauger, M. A. 1950. Sugar and sugar products, Journal of the $A O A C, 57(2): 337-341$.

Nelson, N. 1944. A photometric adaptation of the Somogyi method for the determination of glicose. J. Biol. Chem., 153:375-380.

Noda, H. 1979. Potencialidade da cultura do feijão macuco (Pachyrrhizus tuberosus) In: Von Der Pahlen A.; W. Kerr E.; Paiva W. de O; Rahman F.; Yuyama K.; Von Der Pahlen E.; Noda $\mathrm{H}$. (eds). Introdução à horticultura e fruticultura no Amazonas. Manaus, $\mathrm{CNPq} /$ INPA/ SUFRAMA. p. 58-65.

Noda, H.; Paiva, W, O.; Bueno, C. R. 1984. Hortaliças da Amazônia. Ciência Hoje, 3(13):32-37.
Pandey, R. K. 1983. Effects of leaf and flower removal on seed yield of lentil (Lens esculenta L.). J. Agric. Sci., 100:493-503.

Pechan, P. A.; Morgan, D. G. 1985. Defoliation and its effects on pod and seed development in vil seed rape (Brassica napus L.). J. Exp. Bot., 36(164):458-468.

Pimentel Gomes, F. 1977. Curso de estatistica experimental. São Paulo, Livraria Nobel S. A. 430p.

Sales, A. M. 1993. Dados bioquimicos de Pachyrrhizus tuberosus e $P$. erosus. ITAL, Campinas (mimeografado). 03p.

SAS 1989. Statistical Analysis System - Users guide, release ed. 6.04 Cary, NC SAS Institute Inc. $843 p$.

Wilkerson, G. G; Jonnes, J. W.; Poe, S. L. 1984. Effects of the defoliation on peanut plant growth. Crop Sci., 24(3):531-536.

Yemm, E. W.; Cocking, E. C. 1955. The determination of aminoacids with ninhydrin. Analyst, 80:209-213. 